\title{
MTHFR polymorphism and red cell folate levels are not useful as biomarkers of methotrexate efficacy and toxicity in children with juvenile idiopathic arthritis J Tuková1, M Hroch² and P Doležalová*1
}

\author{
Address: ${ }^{1}$ Department of Paediatrics and Adolescent Medicine, 1st Medical School, Charles University, Prague, Czech Republic and ${ }^{2}$ Department \\ of Pharmacology, Medical School, Charles University, Hradec Králové, Czech Republic \\ * Corresponding author
}

\author{
from 15th Paediatric Rheumatology European Society (PreS) Congress \\ London, UK. 14-17 September 2008 \\ Published: 15 September 2008 \\ Pediatric Rheumatology 2008, 6(SuppI I):PI6 doi:I0.I 186/I546-0096-6-SI-PI6
}

This abstract is available from: http://www.ped-rheum.com/content/6/SI/PI6

(c) 2008 Tuková et al; licensee BioMed Central Ltd.

\section{Introduction}

In adults with rheumatoid arthritis several polymorphisms of C677T genotype (CT and TT) were associated with increased toxicity and higher methotrexate (MTX) efficacy. Homozygote CC polymorphism of A1298C genotype was associated with toxicity.

\begin{abstract}
Aim
To evaluate usefulness of MTHFR polymorphism and folate concentration assessment for prediction of toxicity and efficacy in children with juvenile idiopathic arthritis (JIA). To test association between MTHFR polymorphism and MTX polyglutamate concentration in erythrocytes (EMTX).
\end{abstract}

\section{Patients and methods}

In 46 MTX treated children with JIA C677T and A1298C polymorphisms of MTHFR, red cell folate $(<800 \mathrm{nmol} / \mathrm{l}$ vs. $>800$ ) and erythrocyte EMTX concentration were studied using previously described methods.

\section{Results}

The prevalence of CT and TT genotype was 37 and 13\%, distribution of AC and CC alleles 43 and 9\%, respectively. MTX toxicity was noticed in $41 \%$ of children (GI complaints, raised transaminases, alopecia). $66 \%$ of patients were classified as MTX responders. Folate concentration was below $800 \mathrm{nmol} / \mathrm{l}$ in $28 \%$. Presence of neither of MTHFR polymorphisms correlated with side effects $(\mathrm{p}=$
$0,71, \chi^{2}$ test $)$, clinical efficacy ( $\mathrm{p}=0,18, \chi^{2}$ test), quartiles of EMTX $(p=0,33)$ or folate concentration $(p=0,71)$.

\section{Conclusion}

We have not found MTHFR polymorphism assessment helpful as a biomarker for prediction of clinical efficacy or toxicity in children with JIA. We have shown absence of association of MTHFR genotype with efficacy of MTX therapy. 